\title{
Study to Assess the Status of Hepatitis B Vaccination and Factors Affecting Antibody Titers Level for Hepatitis B to Various Health Care Workers and Medical Students in Tertiary Healthcare Setup in Himachal Pradesh
}

\author{
Aditya Rana ${ }^{1}$, Subhash Chand Jaryal ${ }^{2}$, Anuradha Sood ${ }^{3}$, Anuradha Chaudhary ${ }^{4}$, \\ Isampreet Kaur $^{5}$ \\ ${ }^{1}$ JR, Department of Microbiology, DRPGMC Kangra at Tanda(H.P.) \\ ${ }^{2}$ Professor and Head of the Department, Department of Microbiology, DRPGMC, Kangra at Tanda(H.P.) \\ ${ }^{3}$ Associate Professor, Department of Microbiology, DRPGMC, Kangra at Tanda(H.P.) \\ ${ }^{4}$ SR, Department of Microbiology, DRPGMC, Kangra at Tanda(H.P.) \\ ${ }^{5}$ Assistant Professor, Department of Microbiology, DRPGMC, Kangra at Tanda(H.P.)
}

Corresponding Author: Subhash Chand Jaryal

\begin{abstract}
Background: Hepatitis B (HBV) is one of the most important occupational hazards among the medical student and healthcare workers (HCW's) due to risk of exposure to infected bodily fluids and blood. This study aimed to assess status of $\mathrm{HBV}$ vaccination and factors affecting anti-HBs titres levels for $\mathrm{HBV}$ in $\mathrm{HCW}$ and medical students.

Material and Method: It was a prospective, descriptive and cross sectional study done at the Department of Microbiology, DRPGMC Kangra at Tanda (H.P). Randomly 215 HCW's and medical students were taken in the study who fulfilled the inclusion criteria.

Results: Total of 215 subjects were included in the study. Males were 89 and females were 126. 182 subjects were vaccinated and 33 were unvaccinated for hepatitis B. Out of 182 vaccinated 137 were completely vaccinated. Significant correlation was seen with decrease in antibody titers with gender, duration of vaccination and smoking.

Conclusion: Vaccination should be mandatory for every $\mathrm{HCW}$ and medical student entering the health institutions. The factors affecting the antibody titers must be evaluated and antibody titers must be reviewed from time to time. The need for a booster dose can be made mandatory at least for healthcare professionals.
\end{abstract}

Key words: Hepatitis B virus, Vaccination, Antibody titers, HCW

\section{INTRODUCTION}

The human Hepatitis B Virus (HBV) is the prototype member of the family Hepadnaviridae[1] WHO estimates that in 2015, 257 million people were living with chronic hepatitis B infection (defined as hepatitis B surface antigen positive). In 2015, hepatitis B resulted in an estimated 887000 deaths, mostly from cirrhosis and hepatocellular carcinoma.[2]

India has intermediate endemicity of hepatitis B with hepatitis B surface antigen HBsAg prevalence between 2\% and $7 \%$. India accounts for 10-15\% of the entire pool of Hepatitis B carriers in the world. hepatitis B carriers in India account for 50 million.[3]

Hepatitis B infection is one of the most important occupational hazard among the medical students and healthcare workers(HCW's) due to their risk of exposure to infected bodily fluids and blood. According to WHO, annually $5.9 \%$ of $\mathrm{HCW}$ are exposed to blood borne 
Aditya Rana et.al. Study to assess the status of Hepatitis B vaccination and factors affecting antibody titers level for Hepatitis B to various health care workers and medical students in tertiary healthcare setup in Himachal Pradesh.

HBV infection which corresponds to about 66,000 globally.[4]

Vaccination for HBV is the foremost in protection of many lives globally. In this study we aim for assessing the status of Hepatitis B vaccination and factors affecting the antibody titers in the long run.

\section{MATERIAL AND METHODS}

A prospective, descriptive and cross sectional hospital based study was conducted in Department of Microbiology, DRPGMC Kangra at Tanda, Himachal Pradesh. 215 blood samples were collected from various HCW and medical students who fulfill the inclusion criteria with consent and aged more than 18 years.

Three to five $\mathrm{ml}$ of blood was collected under aseptic precautions. Serum separation was performed by centrifugation of the blood sample at 3000rpm for 5 minutes at room temperature. Anti-HBs

\section{Status of vaccination}

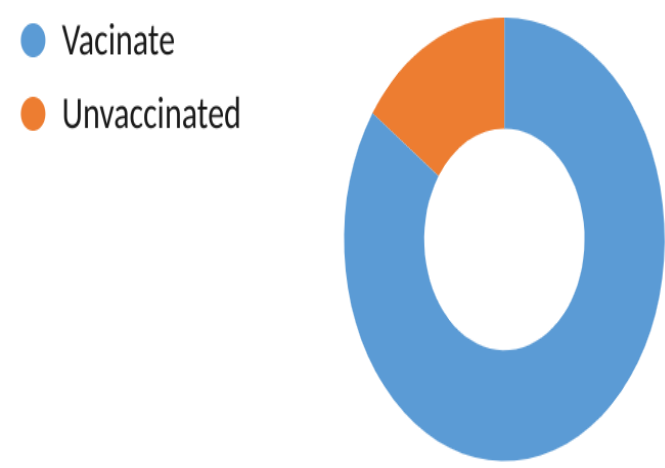

Figure 1: Status of vaccination

Distribution on the basis of sex

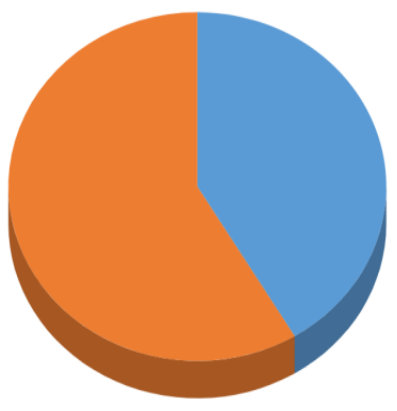

Figure 3: Distribution on the basis of sex antibody levels were detected by Enzyme Linked Immunosorbent Assay using (Dia.Pro, Italy) kit strictly adhering to the manufacturer's protocol.

\section{RESULTS}

There were 215 subjects of which $182(85 \%)$ were vaccinated and $33(15 \%)$ were unvaccinated. (Fig. 1) Out of 33 unvaccinated $24(57.1 \%)$ were class IV workers and 9(14\%) were medical students. (Fig. 2)

$89(41.4 \%)$ were males and 126(58.6\%) were females. (Fig. 3) Out of 182 subjects $137(75.2 \%)$ were fully vaccinated and the rest were partially vaccinated. Age groups taken were between 18 to 60 years. Majority $122(56.7 \%)$ were between 18-30 years, followed by $58(26.9 \%)$ were between 41 to 60 and least $35(16.2 \%)$ were between 31 to 40 years. (Fig. 4)

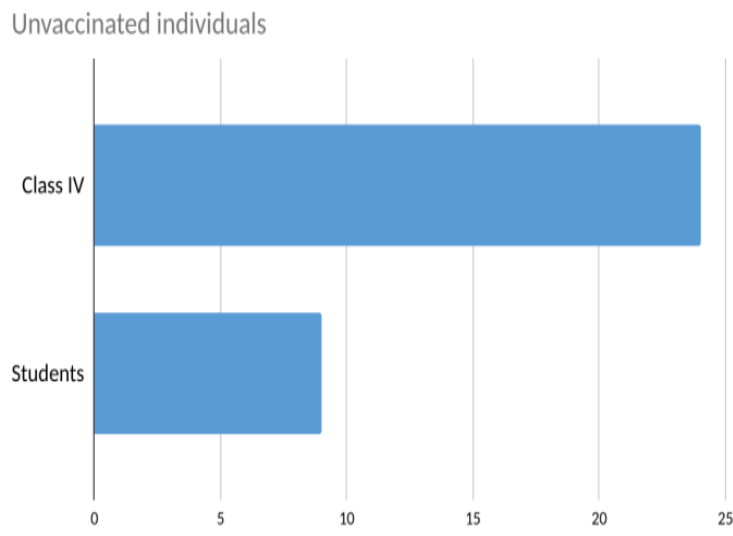

Figure 2: Unvaccinated individuals

Distribution of subjects on the basis of age

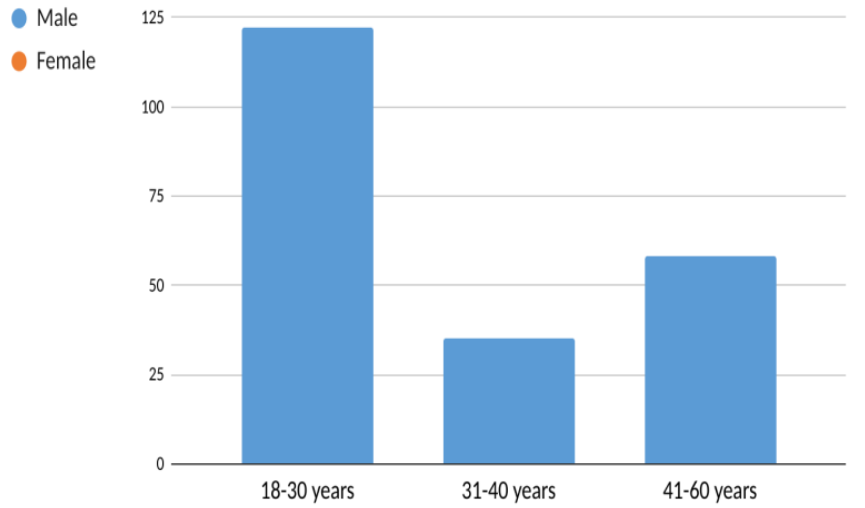

Figure 4: Distribution on the basis of age 
Aditya Rana et.al. Study to assess the status of Hepatitis B vaccination and factors affecting antibody titers level for Hepatitis B to various health care workers and medical students in tertiary healthcare setup in Himachal Pradesh.

Majority of the subjects were in range of normal BMI 145(22.3\%) followed by overweight $48(22.3 \%)$, obese $17(7.9 \%)$ and least were underweight $5(2.3 \%)$. Doctors were in preponderance $73(34 \%)$ followed by medical students $62(19.5 \%)$ and least were lab technicians $15(7 \%)$. Work experience with less than 5 years was predominant in our study with $71(33 \%)$. (Table 1)

Table 1: Distribution of various parameters

\begin{tabular}{|l|l|l|}
\hline $\mathbf{B M I}\left(\mathbf{K g} / \mathbf{m}^{\mathbf{2}}\right)$ & Number(n) & Percentage (\%) \\
\hline Underweight $(<18.5)$ & 5 & $2.3 \%$ \\
\hline Normal $(18.5-22.9)$ & 145 & $67.4 \%$ \\
\hline Overweight $(23.0-24.9)$ & 48 & $22.3 \%$ \\
\hline Obese $(>24.9)$ & 17 & $7.9 \%$ \\
\hline Occupation & Number(n) & Percentage (\%) \\
\hline Doctors & 73 & $34 \%$ \\
\hline Students & 62 & $19.5 \%$ \\
\hline Class IV workers & 42 & $10.7 \%$ \\
\hline Nurses & 23 & $28.8 \%$ \\
\hline Lab Technicians & 15 & $7.0 \%$ \\
\hline Work experience & Number $(\mathbf{n})$ & Percentage $(\%)$ \\
\hline Nil & 62 & $28.8 \%$ \\
\hline$\leq 5$ years & 71 & $33 \%$ \\
\hline 6-10 years & 29 & $13.5 \%$ \\
\hline$>10$ years & 53 & $24.7 \%$ \\
\hline
\end{tabular}

Out of 182 vaccinated individuals $128(70.3 \%)$ had a history of vaccination of $\leq 5$ years followed by $28(15.3 \%)$ with more than 10 years and 26(14.2\%) with $6-10$ years of vaccination history.(Table 1)

Risk factors associated with altered immunity, majority of subjects $37(20.3 \%)$ were alcoholic followed by smokers 25(13.7\%), Hypertensive 10(5.4\%) and none of the subjects were suffering from cancer. (Table 2)

Table 2: Risk factors for altered immunity

\begin{tabular}{|l|l|l|}
\hline $\begin{array}{l}\text { Risk Factors for altered } \\
\text { immunity }\end{array}$ & $\begin{array}{l}\text { Number } \\
(\mathbf{n})\end{array}$ & $\begin{array}{l}\text { Percentage } \\
(\%)\end{array}$ \\
\hline Alcohol & 37 & $20.3 \%$ \\
\hline Smoking & 25 & $13.7 \%$ \\
\hline Hypertension & 10 & $5.4 \%$ \\
\hline Jaundice & 7 & $3.8 \%$ \\
\hline Diabete Mellitus & 5 & $2.7 \%$ \\
\hline Chronic illness & 5 & $2.7 \%$ \\
\hline Immunomodulating drugs & 1 & $0.5 \%$ \\
\hline Cancer & 0 & $0 \%$ \\
\hline
\end{tabular}

Mean antibody titers $223.3(\mathrm{mIU} / \mathrm{ml})$ were maximum in the age group 18-30 years and least $127.6(\mathrm{mIU} / \mathrm{ml})$ in age more than 40 years. Females have significantly higher antibody titers in comparison to males $(\mathrm{p}=0.002)$ (Table 3$)$

No significance correlation in antibody titers and BMI was seen in the study. Significant decrease was seen in antibody titers with duration of vaccination. In our study smokers and alcoholics had significant decrease in antibody titers to non smokers and non alcoholics $(\mathrm{p}=0.0037$, 0.085). (Table 3) Negative correlation was seen in decreasing antibody titers with increasing age.(Fig. 5)

Table 3: Factors affecting Antibody Titers

\begin{tabular}{|l|l|}
\hline Age & Mean Ab Titer $(\mathbf{m I U} / \mathbf{m l})$ \\
\hline $18-30$ & 223.3 \\
\hline $31-40$ & 139.1 \\
\hline $41-60$ & 127.6 \\
\hline Gender & Antibody titers $\quad$ P value $\mathbf{0 . 0 0 2})$ \\
\hline Male & $142.8 \pm 142.4$ \\
\hline Female & $211.9 \pm 164.6$ \\
\hline Duration of Vaccination & Ab titers $($ Median) $(\mathbf{P}$ value $<\mathbf{0 . 0 0 0 1})$ \\
\hline$\leq$ 5 years & $319.0[200.0,378.0]$ \\
\hline 6-10 years & $87.0[70.7,115.0]$ \\
\hline$>10$ years & $1.0[1.0,3.0]$ \\
\hline
\end{tabular}

\begin{tabular}{|l|l|l|l|}
\hline Risk Factors & & Mean antibody titers(mIU/ml) & P value \\
\hline Alcoholic & Alcoholic & $142.7 \pm 153.6$ & 0.085 \\
& Non Alcoholic & $194.7 \pm 169.0$ & \\
\hline Smoking & Smoker & $120.4 \pm 145.1$ & 0.037 \\
& Non smoker & $194.4 \pm 168.5$ & \\
\hline Hypertension & Hypertensive & $201.7 \pm 174.6$ & 0.759 \\
& Non hypertensive & $185 \pm 167.3$ & \\
\hline Chronic illness & Chronic illness & $147 \pm 189.3$ & 0.601 \\
& Healthy & $186.7 \pm 167.1$ & 0.628 \\
\hline Diabetes & Diabetic & $184.9 \pm 166.8$ & \\
& Non diabetic & $221.7 \pm 206.8$ & \\
\hline
\end{tabular}


Aditya Rana et.al. Study to assess the status of Hepatitis B vaccination and factors affecting antibody titers level for Hepatitis B to various health care workers and medical students in tertiary healthcare setup in Himachal Pradesh.

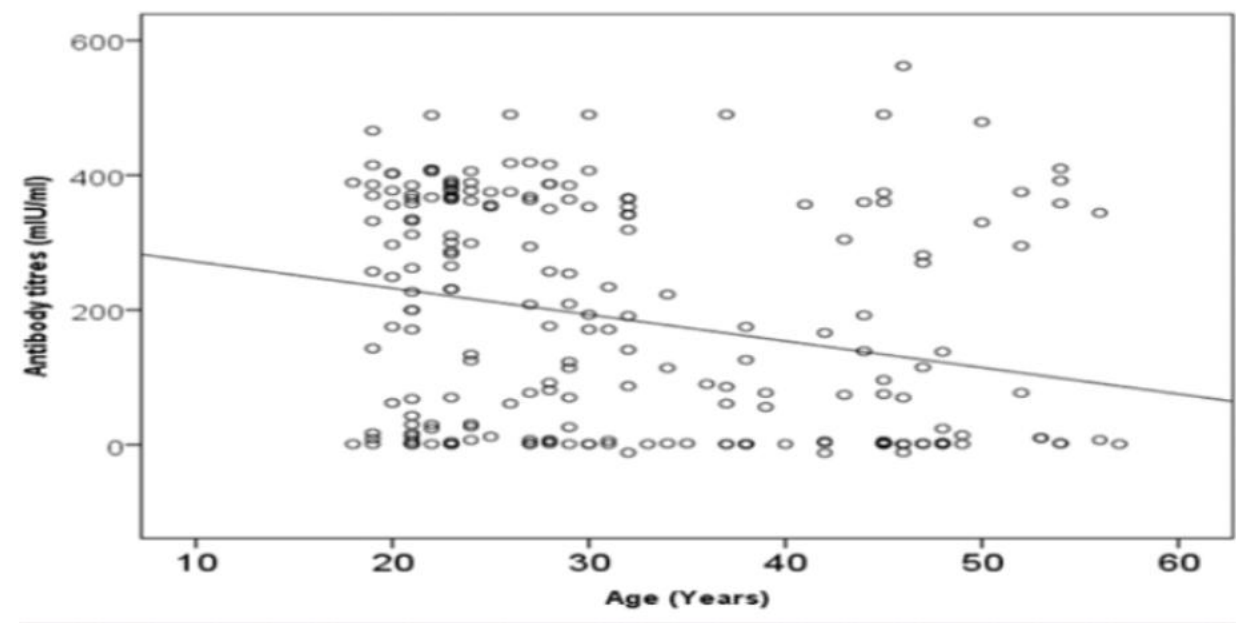

Figure: 5 Showing negative correlation between increasing age and decreasing antibody titers

\section{DISCUSSION}

Hepatitis B is vaccine preventable disease. In our study 33(15\%) subjects were unvaccinated and $182 \quad(75 \%)$ were vaccinated. Kumar et al in their study also showed $43.9 \%$ of unvaccinated healthcare workers for HBV.[4] Majority of the unvaccinated individuals were class IV workers 24(57.1\%) and 9(14.5\%) were medical students. In our study by Batra et al showed least vaccination in Class IV workers. This could be due to lack of awareness of the disease in this group of HCW's.[6]

Majority $223.3 \quad(\mathrm{mIU} / \mathrm{ml})$ mean antibody titers for HBV vaccination were seen in the 18-30 year age group. This could be justifiable by the history of recent vaccination in this age group. Significant correlation was seen in antibody titers in females to males. Antibody titers were higher in females in comparison to males. Study by Stephaine et al in their study showed females generate higher immune response due to genetic, hormonal and $\mathrm{mi}$ RNA factors.[7]

In contrast to our study results no correlation was seen in antibody titers to BMI. Scott D et al in their study showed obesity leads to decrease in immune response to HBV vaccination.[8]

Significant decreases in antibody titincludeers were observed in smokers and alcoholics. Similarly in study by Yang et al and Tagliabue et al showed a deteriorating effect of immune response in smokers to non smokers. $[9,10]$ Averhoff et al showed significant decrease in antibody titers of HBV in smokers.[11]

Remarkable reductions in antibody titers were seen with increasing age in our study. In similarity to our result study by Basireddy $\mathrm{P}$ et al, Farahnaz et al and Sahana et al showed decrease in antibody titers with increasing age.[12-14]

\section{CONCLUSION}

We recommend that all HCW's and medical students should be vaccinated for Hepatitis B. There is a need for strict implementation of the policy of Hepatitis B immunizations; periodic follow up for the level of antibody titers is required in every health care setting. It's not only to ensure safety of health care workers but also to reduce rate of transmission hence reducing nosocomial transmission which is very much desired in source limited countries.

HBV campaigns should be organized to sensitize HCW's on this disease. Campaign should include improved mass media programs, broadcasting health talks and programs.

Acknowledgement: None

Conflict of Interest: None

Source of Funding: None 
Aditya Rana et.al. Study to assess the status of Hepatitis B vaccination and factors affecting antibody titers level for Hepatitis B to various health care workers and medical students in tertiary healthcare setup in Himachal Pradesh.

\section{Ethical Approval: Approved}

\section{REFERENCES}

1. Ganem D, Schneider RJ, Knipe DM, Howley PM, Griffin DE, Martin MA, et al. Hepadnaviridae and their replication. In Philadelphia, PA: Lippincott-Raven Publishers; 2001.

2. World Health Organisation. Hepatitis B. Who.int. Available from: https://www.who.int/news-room/factsheets/detail/Hepatitis-B.

3. National Centre for Disease Control India. News letter. 2014 Jan-Mar;3(1)

4. Rapiti E, Hutin Y. NIOSH Alert: preventing needle stick injuries in PrüssUstün A. Am J Ind Med. 2005;48:482-490.

5. Kumar KA, Baghal PK, Shukla CB, Jain MK. Prevalence of hepatitis B surface antigen (HBsAg) amongHealth Care Workers. Indian J Comm Med. 2000;25: 93-96.

6. Batra V, Goswami A, Dadhich S, Kothari D, Bhargava N.Hepatitis B immunization in healthcare workers. Ann Gastroenterol.2015;28:276-80.

7. Fischinger $\mathrm{S}$, Boudreau CM, Butler AL, Streeck H, Alter G. Sex differences in vaccine-induced humoral immunity. Semin Immunopathol. 2019;41(2):239-49.

8. Painter, S. D., Ovsyannikova, I. G., \& Poland, G. A. (2015). The weight of obesity on the human immune response to vaccination. Vaccine, 33(36), 44224429.

9. Yang S, Tian G, Cui Y, Ding C, Deng $\mathrm{M}, \mathrm{Yu} \mathrm{C}$, et al. Factors influencing immunologic response to hepatitis $\mathrm{B}$ vaccine in adults. Sci Rep [Internet]. 2016;6(1).

10. Tagliabue C, Principi N, Giavoli C, Esposito S. Obesity: impact of infections and response to vaccines. Eur $\mathrm{J}$ Clin Microbiol Infect Dis. 2016;35(3):325-31.

11. Averhoff F, Mahoney F, Coleman P, Schatz G, Hurwitz E, Margolis H. Immunogenicity of hepatitis B Vaccines. Implications for persons at occupational risk of hepatitis B virus infection. Am J Prev Med. 1998 Jul;15(1):1-8.

12. Basireddy P, Avileli S, Beldono N, Gundela SL. Evaluation of immune response to hepatitis $\mathrm{B}$ vaccine in healthcare workers at a tertiary care hospital. Indian J Med Microbiol. 2018; 36(3):397-400.

13. Joukar F, Mansour-Ghanaei F, Naghipour MR, Asgharnezhad M. Immune response to hepatitis B vaccine among north Iranian healthcare workers and its related factors. J Infect Dev Ctries. 2017;11(6): 501-7.

14. Sahana HV, Sarala N, Prasad SR. Decrease in Anti-HBs Antibodies over Time in Medical Students and Healthcare Workers after Hepatitis B Vaccination. Biomed Res Int.2017;2017: 1327492.

How to cite this article: Rana A, Jaryal SC, Sood A et.al. Study to assess the status of Hepatitis B vaccination and factors affecting antibody titers level for Hepatitis B to various health care workers and medical students in tertiary healthcare setup in Himachal Pradesh. International Journal of Research and Review. 2021; 8(9): 242-246. DOI: https://doi.org/10. 52403/ijrr.20210933 